\title{
FITOTECNIA
}

\section{PARÂMETROS BIOMÉTRICOS E PRODUTIVIDADE DA CANA-DE-AÇÚCAR APÓS TOMBAMENTO DOS COLMOS ( $\left.{ }^{1}\right)$}

\author{
SAMIRA DOMINGUES CARLIN $\left({ }^{2 *}\right)$; MARCELO DE ALMEIDA SILVA $\left({ }^{2}\right)$; RAFFAELLA ROSSETTO $\left({ }^{3}\right)$
}

\begin{abstract}
RESUMO
Os efeitos do tombamento dos colmos à produtividade da cana-de-açúcar são do interesse de pesquisadores em diversas regiões do mundo; no Brasil, entretanto, essa pesquisa é escassa. O objetivo deste trabalho foi avaliar os efeitos causados pelo tombamento e o aparecimento de brotões em parâmetros biométricos e na produtividade de duas variedades de cana-de-açúcar. O experimento foi desenvolvido no município de Jaú (SP), no período de março de 2003 a setembro de 2004. O delineamento experimental foi o de blocos ao acaso, em fatorial com quatro tratamentos (duas variedades e dois manejos de condução da cultura) em quatro repetições. Os manejos consistiram de plantas mantidas eretas e de plantas sujeitas ao tombamento dos colmos. Avaliaram-se dados biométricos e quantificaram-se brotões aos 5, 50, 95, 140 e 185 dias após o tombamento (DAT). Os valores de comprimento e números de colmos foram aumentados pelo tombamento até $95 \mathrm{DAT}$, mas a emissão de brotões foi favorecida, com conseqüente aumento da produtividade agrícola das variedades. Esses resultados são indicativos de que a colheita de colmos deve ser realizada após 95 dias do tombamento das plantas a fim de se evitar excesso de brotões na matéria-prima.
\end{abstract}

Palavras-chave: Saccharum spp., hábito de crescimento, brotão, acamamento.

\section{ABSTRACT \\ BIOMETRIC PARAMETERS AND PRODUCTIVITY OF SUGARCANE AFTER STALK LODGING}

Effects by stalk lodging on productivity of sugarcane are of interest of researchers in several regions around of the world. However, this research still is scarce in Brazil. The objective of this work was to evaluate the effects caused by lodging and emergence of suckers on biometric parameters and productivity of two cultivars. The experiment was carried out in Jaú, State of São Paulo, between March 2003 and September 2004, in the completely randomized blocks, in a factorial design with four treatments (two varieties and two crop managements) in four replicates. The managements consisted of plants maintained erect and under stalk lodging. Biometric data and amount of suckers were assessed at 5, 50, 95, 140 and 185 days after lodging (DAL). Lodging increased the stalk length and stalk number up to 95 DAL, but the emergence of suckers was favored, for both cultivars and consequently the stalk productivity was increased. Harvest should be done after 95 DAL in order to avoid excess of young stalks.

Key words: Saccharum spp., growing habit, sucker, lodging.

$\left({ }^{1}\right)$ Apresentado pelo primeiro autor como parte das exigências para obtenção do título de Mestre em Agronomia no Programa de Pós-Graduação em Agricultura Tropical e Subtropical, Tecnologia da Produção Agrícola do Instituto Agronômico - IAC. Recebido para publicação em 28 de dezembro de 2006 e aceito em 18 de abril de 2008.

(2) Agência Paulista de Tecnologia dos Agronegócios, Regional Centro-Oeste, Rodovia SP 304 km 304, Caixa Postal 66, 17201-970 Jaú (SP). E-mail: sdcarlin@apta.sp.gov.br (*) Autora correspondente; marcelosilva@apta.sp.gov.br

$\left({ }^{3}\right)$ Agência Paulista de Tecnologia dos Agronegócios, Regional Centro-Sul, Rodovia Piracicaba - Rio Claro km 02, Caixa Postal 28, 13400-970 Piracicaba (SP). E-mail: raffaella@apta.sp.gov.br 


\section{INTRODUÇÃO}

A cana-de-açúcar tem sido cultivada no Brasil desde o século XVI. Atualmente, é de grande importância econômica, social e ambiental, em função de grandes áreas plantadas, e da geração de matériaprima para as agroindústrias do açúcar, álcool e subprodutos, sendo importante fonte de energia renovável, aspecto relevante quanto à questão de sustentabilidade ambiental (BRASIL, 2006), além de ser fonte de geração de muitos empregos e renda no meio rural brasileiro. Vários fatores, entretanto, podem ter influência na produtividade da cana-de-açúcar. Dentre esses, um de grande importância e do interesse de produtores e pesquisadores em diversas regiões produtoras no mundo é o tombamento das plantas (SINGH et al., 2000; AMAYA et al., 2000; JACKSON et al., 2000; Berding e Hurney, 2005; Silva e Caputo, 2005).

O tombamento é considerado a queda das plantas em decorrência de vários fatores, como altura dos colmos; hábito de crescimento; fenômenos ambientais, como ventos; algum tipo de deficiência nutricional nos colmos ou raízes; ou elevada massa dos colmos (SINGH et al., 2000). Deve-se salientar que, os colmos tombados são classificados como aqueles deslocados mais do que $60-70^{\circ}$ da vertical (AMAYA et al., 2000).

Em trabalho realizado na Austrália, SINGH et al. (2000) quantificaram o efeito do tombamento comparando parcelas com colmos acamados àquelas com colmos mantidos eretos. Observou-se que no tratamento tutorado, foram produzidos significativamente $11 \%$ a $19 \%$ mais cana do que no tombado. No único e recente trabalho realizado no Brasil, Silva e Caputo (2005) avaliaram as conseqüências do tombamento em três variedades de cana-de-açúcar: IAC91-5155, indicada como padrão devido ao porte ereto, e RB835486 e SP87-344, consideradas decumbentes. Observaram que, durante a colheita, ocorreu um aumento na produtividade de colmos nas parcelas mantidas eretas, que foi variável de $12,8 \%$ na RB835486 e de $20,4 \%$ na SP87-344, além do acréscimo na produção de açúcar.

Com o tombamento também é induzido o aparecimento de brotões, que são brotos desenvolvidos após a estabilização dos colmos principais na cultura, e cujo comportamento é similar ao de uma cana jovem. Diferenciam-se, todavia, pelos caules mais grossos e folhas mais largas e curtas do que os dos colmos principais. Ao serem colhidos juntamente com a cana madura, há uma tendência para diminuição da qualidade da matéria-prima, devido ao reduzido teor de sacarose e elevado teor de açúcares redutores nos mesmos (BERDING et al., 2005).
Por sua vez, num sistema de produção onde se colhe a cana mecanicamente, é economicamente inviável a separação dos brotões dos demais colmos. Nas usinas, com a colheita desses rebentos, aumentase a quantidade de material colhido, transportado e processado visando-se à produção de açúcar e álcool; porém, é diminuída a qualidade da matéria-prima com redução dos lucros na indústria (BONNETT et al., 2004).

JACKSON et al. (2000), ao estudarem a interferência dos brotões na produtividade de diferentes variedades de cana-de-açúcar, classificaram em três classes as variedades sujeitas à emissão de brotões: leves, médias e intensas, conforme a relação entre massa dos brotões e produção de cana, ou seja, de $5 \%, 15 \%$ e $25 \%$ respectivamente.

De acordo com LANDell e Silva (1995), a produtividade agrícola pode ser estimada por parâmetros biométricos. Consideram-se como componentes da produtividade da cana-de-açúcar o diâmetro e comprimento dos colmos, o número de colmos por área - associado à capacidade de perfilhamento, e a densidade do colmo. Todos eles são caracteres genéticos, porém, sujeitos à influência ambiental (SKINNER, 1967).

A grande maioria das referências disponibilizadas na literatura sobre o impacto do tombamento de colmos e da emissão de brotões na produtividade da cana-de-açúcar é proveniente da Austrália e Colômbia. No Brasil, apesar de problemas decorrentes desses dois fatores, o assunto foi pouco estudado em variedades nacionais cultivadas. Portanto, no presente trabalho teve-se como objetivo avaliar resultados sobre os danos causados pelo tombamento e o aparecimento de brotões em parâmetros biométricos e na produtividade da cana-de-açúcar.

\section{MATERIAL E MÉTODOS}

O experimento foi desenvolvido na Unidade de Pesquisa e Desenvolvimento de Jaú (SP), da APTA Regional Centro-Oeste (DDD/APTA/SAA), localizada nas coordenadas de $22^{\circ} 17^{\prime}$ latitude Sul e $48^{\circ} 37^{\prime}$ longitude Oeste, a uma altitude de $580 \mathrm{~m}$. O solo da área caracteriza-se como um Latossolo Vermelho distrófico (PRADO, 2003). O clima predominante da região é Aw (Köppen), com clima seco definido, temperatura média anual de $21,6^{\circ} \mathrm{C}$, umidade média máxima de $77 \%$ em fevereiro e média mínima de $49 \%$ em agosto. A precipitação pluvial média anual contabilizada no período de 1995 a 2004 foi de $1.509 \mathrm{~mm}$.

O plantio foi realizado em 5 de março de 2003 e desenvolvido até 3 de setembro de 2004. As parcelas constituíram-se de nove sulcos de $10 \mathrm{~m}$ de 
comprimento, com espaçamento de 1,5 m entre si, perfazendo uma área útil total de $135 \mathrm{~m}^{2}$. A adubação de plantio foi com $400 \mathrm{~kg} \mathrm{ha}^{-1}$ do adubo formulado 4-14-8. Para o controle de pragas de solo foram aplicados no sulco, antes do plantio, $170 \mathrm{~g}$ de fipronil e 2,5 L de carbofuran em $50 \mathrm{~L}$ de água. Para o controle de plantas daninhas foram aplicados, após o plantio, 2,1 L de ametrina $+2,1 \mathrm{~L}$ de diurex $+1,0 \mathrm{~L}$ de MSMA em $300 \mathrm{~L}$ de água.

A fim de se evitar o tombamento das touceiras, as plantas das parcelas do tratamento ereto foram tutoradas em janeiro de 2004, com mourões de eucalipto de $2,8 \mathrm{~m}$ de comprimento, espaçados na linha a cada $2,5 \mathrm{~m}$. As touceiras foram mantidas eretas por meio de arames entrelaçados a $0,90 \mathrm{~m}$ e $1,80 \mathrm{~m}$ de distância do solo.

O delineamento experimental utilizado foi o de blocos ao acaso em esquema fatorial $2 \times 2$ (duas variedades de cana-de-açúcar e dois manejos da cultura) em quatro repetições, sendo as duas variedades comparadas entre e dentro delas. As variedades estudadas foram: IAC86-2210, de hábito de crescimento semidecumbente, moderadamente resistente ao tombamento e média tendência ao aparecimento de brotões (LANDELL et al., 1997) e SP801842, considerada decumbente com elevada tendência ao tombamento e ao aparecimento de brotões (Copersucar, 1993). Os tratamentos foram correspondentes às plantas mantidas eretas por tutoramento $(\mathrm{T})$ e àquelas com hábito de crescimento natural, ou seja, não tutoradas (NT).

Iniciou-se a coleta dos dados biométricos, cinco dias após ter ocorrido o tombamento das plantas não tutoradas, estabelecendo-se o intervalo de aproximadamente 45 dias entre cinco amostragens. As épocas de coletas dos dados biométricos aos 5, 50, 95, 140 e 185 dias após o tombamento (DAT), foram em $1 .^{\circ}$ de março, 15 de abril, $10^{\circ}$ de junho, 19 de julho e 3 de setembro de 2004 respectivamente. Em cada parcela foi colhida uma amostra de colmos, utilizando-se um gabarito de $1 \mathrm{~m}$ de comprimento, disposto aleatoriamente nas cinco linhas centrais, da parcela útil.

O comprimento de cada colmo foi medido da base até a inserção da folha +3 , por meio de uma fita métrica e o diâmetro, com um paquímetro, na altura de $1 / 3$ do comprimento do colmo da base para a ponta (LANDell e Silva, 1995); em cada colmo foi contado o número de internódios. A amostra foi amarrada e obteve-se sua massa inicial em uma balança; em seguida, em cada amostra, foram retirados os brotões - colmos com alturas maiores de $30 \mathrm{~cm}$ e menores que os colmos principais (HURNEY e BERDING, 2000). Normalmente, possuem diâmetro superior ao dos adultos (BONNETT et al., 2001), avaliados separadamente para obter sua proporção no total de cana produzida. A contagem dos perfilhos na área útil da parcela foi feita após todas as amostragens, adicionando-se o número de colmos determinados com o gabarito e, na colheita final do experimento, adicionaram-se os perfilhos retirados durante as amostragens.

A produtividade de cana-de-açúcar expressa em tonelada de cana por hectare $(\mathrm{TCH})$ foi determinada no momento da colheita do experimento, obtendo-se a massa das plantas nas parcelas com o uso de célula de carga, adicionando-se a quantidade de massa das amostras retiradas durante as amostragens.

O programa estatístico utilizado foi o ESTAT, aplicando-se o teste de Tukey a 5\% de probabilidade, para a comparação entre médias.

\section{RESULTADOS E DISCUSSÃO}

$\mathrm{Na}$ figura 1, observam-se as condições climáticas ocorridas durante o desenvolvimento do experimento (temperaturas máximas e mínimas, juntamente com as precipitações mensais). Esse período é referente da implantação até a colheita do experimento. Na ocorrência de precipitação pluvial de $86,5 \mathrm{~mm}$, em 25/2/2004, com ventos de $52,0 \mathrm{~km} \mathrm{~h}^{-1}$ sentido Sul, foi provocado o tombamento das plantas não tutoradas.

Os dados biométricos estão apresentados na tabela 1. Constataram-se diferenças significativas para comprimento de colmos dentro de variedades, aos 50 DAT. Tanto na variedade IAC86-2210 quanto na SP801842, o comprimento de colmos no tratamento tombado foi significativamente superior ao do tratamento tutorado, nessa data de avaliação. Provavelmente, logo após o tombamento dos colmos, foi induzido o crescimento da cana devido às mudanças hormonais promovidas pelas auxinas (TAIZ e ZEIGER, 2004), com conseqüente alongamento dos colmos e, a partir dos $95 \mathrm{DAT}$, com o fim do impacto do tombamento, as concentrações de auxinas entre colmos tombados e não tombados foram igualadas, eliminando-se as diferenças. Aliado a esse fato, até fim de abril de 2004 (50 DAT), a cana-de-açúcar ainda estava em fase de crescimento, associada à idade (RAmesh e Mahadevaswamy, 2000) e às condições climáticas nesse período (Figura 1).

CAPUTO (2003), no entanto, verificou resultados opostos, em que os valores de comprimento de colmos nas touceiras mantidas eretas das variedades decumbentes foram maiores do que nas touceiras não tutoradas, na maioria das avaliações realizadas. 


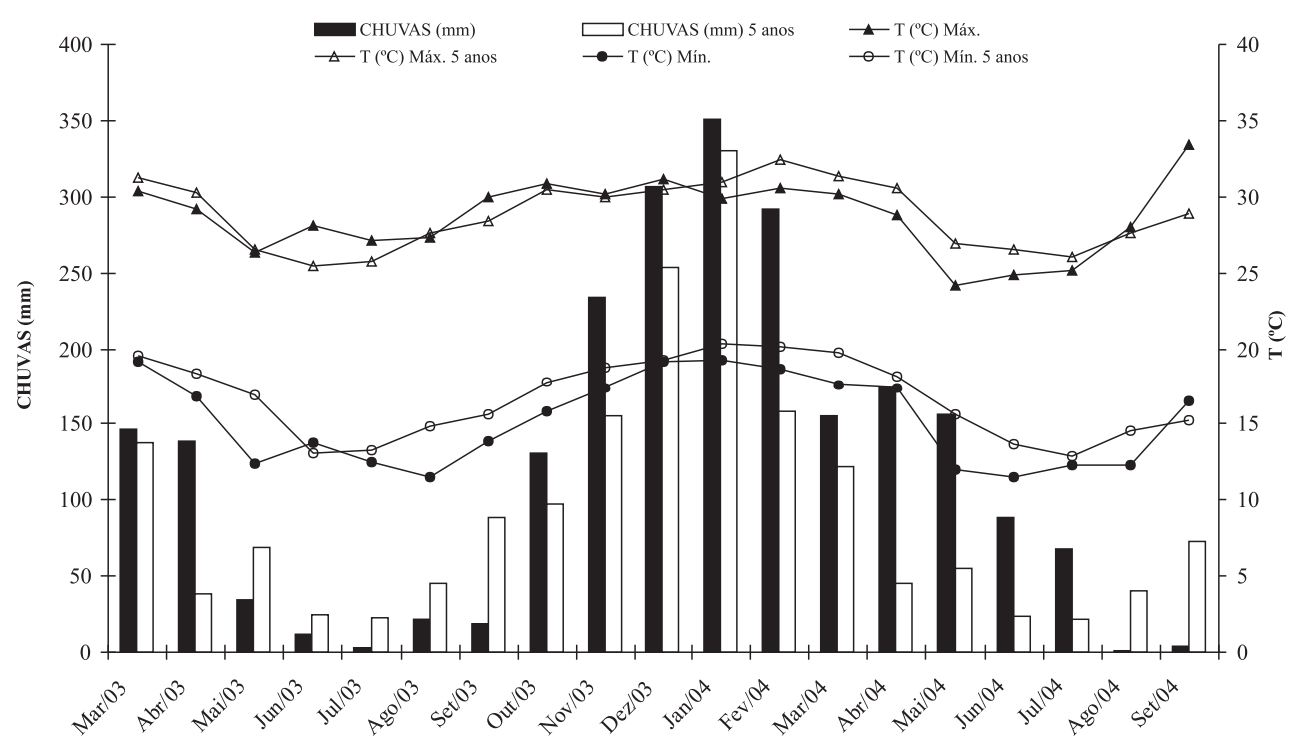

Figura 1. Valores de quantidades de chuva e de temperaturas, registrados de março de 2003 a setembro de 2004 . Jaú $(\mathrm{SP})$.

Tabela 1. Comprimento de colmos, diâmetro de colmos e número de internódios em variedades de cana-de-açúcar, em função do manejo de plantas e dos dias após o tombamento. Jaú (SP), Safra 2003/2004

\begin{tabular}{|c|c|c|c|c|c|c|}
\hline \multirow{2}{*}{ Parâmetros } & \multirow{2}{*}{ Variedades } & \multicolumn{5}{|c|}{ Dias após o tombamento } \\
\hline & & 5 & 50 & 95 & 140 & 185 \\
\hline & & & 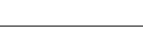 & $-\mathrm{cm}-$ & 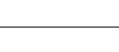 & + \\
\hline \multirow[t]{5}{*}{$\mathrm{C}$} & IAC86-2210 (T) & 170,64 & 200,85 B & 241,36 & 289,10 & 278,78 \\
\hline & IAC86-2210 (NT) & 193,47 & $232,39 \mathrm{~A}$ & 243,26 & 273,02 & 250,71 \\
\hline & SP80-1842 (T) & 190,55 & $245,45 \mathrm{~B}$ & 287,63 & 308,32 & 301,04 \\
\hline & SP80-1842 (NT) & 205,14 & $251,80 \mathrm{~A}$ & 305,39 & 315,97 & 313,63 \\
\hline & CV $(\%)$ & 9,3 & 7,2 & 8,9 & 8,5 & 7,3 \\
\hline \multirow[t]{5}{*}{$\mathrm{D}$} & IAC86-2210 (T) & 2,26 & 2,49 & $2,52 \mathrm{~B}$ & 2,58 & 2,55 \\
\hline & IAC86-2210 (NT) & 2,35 & 2,74 & $2,66 \mathrm{~A}$ & 2,69 & 2,67 \\
\hline & SP80-1842 (T) & 2,28 & 2,52 & $2,55 \mathrm{~B}$ & 2,72 & 2,74 \\
\hline & SP80-1842 (NT) & 2,18 & 2,66 & $2,74 \mathrm{~A}$ & 2,59 & 2,74 \\
\hline & CV $(\%)$ & 5,2 & 6,8 & 5,4 & 4,3 & 5,2 \\
\hline \multirow[t]{5}{*}{ NI } & IAC86-2210 (T) & 15,97 B & $17,97 \mathrm{~B}$ & 22,15 & 23,35 & 26,05 \\
\hline & IAC86-2210 (NT) & $18,17 \mathrm{~A}$ & $20,68 \mathrm{~A}$ & 22,23 & 23,83 & 25,02 \\
\hline & SP80-1842 (T) & 16,21 & 19,16 & 23,59 & 24,26 & 26,80 \\
\hline & SP80-1842 (NT) & 16,67 & 19,83 & 24,33 & 23,00 & 25,92 \\
\hline & CV $(\%)$ & 6,9 & 9,4 & 8,8 & 10,3 & 9,4 \\
\hline
\end{tabular}

Médias na coluna seguidas de letras diferentes são diferentes entre si a $5 \%$ de probabilidade pelo teste de Tukey.

C: comprimento de colmos; D: diâmetro de colmos; NI: número de internódios

T: tutorada; NT: não tutorada. 
Ainda, segundo a autora, a razão dessa diferença se deve às elevadas temperaturas constatadas no período de agosto a novembro de 2002, já que a precipitação pluvial acumulada em agosto $(69,8 \mathrm{~mm})$ não é freqüente para o período. Com isso, o crescimento dos colmos mantidos eretos foi possivelmente favorecido, nas parcelas, visto que, no fim do ciclo, já se constatava algum tombamento de plantas não tutoradas das variedades decumbentes RB835486 e SP87-344.

Conforme os dados obtidos para diâmetro de colmos, este parâmetro foi pouco afetado pelo tombamento, sendo tal efeito observado apenas aos 95 dias após o tombamento das plantas nas parcelas (Tabela 1). Para as variedades, houve diferenças entre manejos, sendo estas superiores para o tratamento não tutorado. A esses resultados contrapõem-se os de BERDING e HuRney (2005), segundo os quais, os valores dos diâmetros nas canas mantidas eretas foram superiores aos naquelas tombadas, tanto em canaplanta quanto em cana-soca. CAPUTO (2003), entretanto, também não obteve diferenças significativas nos diâmetros de colmos entre variedades e tipo de manejo em todo o período de avaliação. Para os resultados aqui apresentados não é atribuída significância prática, pois as avaliações de diâmetro foram realizadas em segmentos onde o crescimento já estava completo; essas verificações também foram relatadas por Silva e Caputo (2005).

Ainda, pelos dados na tabela 1, constatam-se diferenças no número de internódios apenas na IAC86-2210, e aos 5 e 50 DAT, os valores foram significativamente maiores para esse parâmetro, devido ao tombamento dos colmos. CAPUTO (2003) verificou diferenças significativas apenas para as variedades decumbentes, em que os maiores valores de número de internódios foram nos tratamentos tutorados, no decorrer de todo o período avaliado. Em relação aos dados obtidos para comprimento de colmos, pode-se inferir que, com o tombamento, a divisão celular não é acentuadamente prejudicada, mas seus efeitos são verificados no alongamento celular.

Para número de colmos por metro, com o tombamento promoveu-se valor significativamente maior dos 50 aos 185 DAT nas variedades, com exceção à IAC86-2210 aos 140 dias (Tabela 2). No entanto, em parcelas com tombamento das canas, BERDing e HuRney (2005) obtiveram número de colmos por metro linear inferior àquelas em que as plantas permaneceram eretas, devido, principalmente, ao grande número de colmos mortos. SiNGH et al. (2000) constataram resultados semelhantes em experimento realizado na Austrália, nos quais, dependendo da velocidade, da natureza, da extensão e da freqüência da ocorrência dos tombamentos, com diferentes quantidades de colmos mortos é alterado significativamente o número de colmos na parcela, ao longo de todo o período avaliado.

Neste estudo, não foram verificados colmos mortos, mas sim um pronunciado aumento do número de brotões nas parcelas com tombamento das plantas, e em conseqüência, um aumento na porcentagem do número de brotões em relação ao número de colmos por metro (Tabela 2). Apesar do número de brotões ser uma característica varietal, verificou-se um aumento, nas duas variedades estudadas, principalmente entre 50 e 140 DAT. O surgimento de brotões pode ter sido favorecido pelo período de elevadas precipitações, conforme dados na figura 1 , bem como pelo aumento nas parcelas mantidas eretas entre 95 e $140 \mathrm{DAT}$, visto que a umidade elevada do solo constitui um dos principais fatores externos de estímulo ao aparecimento desses brotos (BERDING et al., 2005; BONNETT et al., 2005).

$\mathrm{Na}$ variedade IAC86-2210, o número de brotões foi aumentado dos 360 aos 495 dias após o plantio, de 1,90 a 5,75 por metro linear. Na SP80-1842, o número desses brotos foi variável de 1,50 para 5,25 por metro linear (Tabela 2). Segundo BonNETT et al. (2001, 2005), em trabalhos realizados na Austrália, o pico de aumento do número de brotões foi estabelecido alguns meses após o plantio - dos 318 aos 429 dias, sendo variável de 1,90 para 7,0 por metro linear, enquanto o número de colmos adultos foi relativamente constante, 13,8 para 13,4 por metro linear no mesmo período.

Aos 185 DAT não foram mais observadas diferenças entre os manejos para número de brotões e para porcentagem do número de brotões em relação ao número de colmos por metro, provavelmente porque, a partir dos 140 DAT, houve crescimento desses brotos até a fase adulta. Para Berding et al. (2005), o rápido crescimento dos brotões se deve, principalmente, à elevada incidência de luz sobre as touceiras, favorecidas pelo tombamento das plantas, associado, contudo, à elevada umidade do solo. Resultados semelhantes foram relatados por HURNEY e BERDING (2000).

No parâmetro massa de colmos por metro linear, foram obtidos valores significativamente maiores dos colmos nas plantas tombadas apenas aos 50 DAT, nas duas variedades estudadas (Tabela 3).

Segundo Landell e Silva (1995), o comprimento dos colmos é um dos componentes da produtividade e, como os valores desse parâmetro foram maiores nas plantas tombadas (Tabela 1), pode ter havido efeito na massa de colmos. 
Tabela 2. Número de colmos, número de brotões e porcentagem do número de brotões por metro em variedades de cana-de-açúcar, em função do manejo de plantas e dos dias após o tombamento. Jaú (SP), safra de $2003 / 2004$

\begin{tabular}{|c|c|c|c|c|c|c|}
\hline \multirow{2}{*}{ Parâmetros } & \multirow{2}{*}{ Variedades } & \multicolumn{5}{|c|}{ Dias após o tombamento } \\
\hline & & 5 & 50 & 95 & 140 & 185 \\
\hline & & & 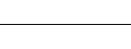 & $-\mathrm{n}^{\mathrm{o}}-$ & 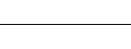 & 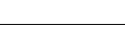 \\
\hline \multirow[t]{5}{*}{ NC } & IAC86-2210 (T) & 13,75 & $12,75 \mathrm{~B}$ & $12,75 \mathrm{~B}$ & 15,00 & $11,75 \mathrm{~B}$ \\
\hline & IAC86-2210 (NT) & 13,25 & $14,25 \mathrm{~A}$ & $13,75 \mathrm{~A}$ & 15,50 & $14,25 \mathrm{~A}$ \\
\hline & SP80-1842 (T) & 12,75 & $11,00 \mathrm{~B}$ & $11,25 \mathrm{~B}$ & $13,25 \mathrm{~B}$ & $10,75 \mathrm{~B}$ \\
\hline & SP80-1842 (NT) & 13,50 & $12,75 \mathrm{~A}$ & $12,50 \mathrm{~A}$ & $17,00 \mathrm{~A}$ & $11,25 \mathrm{~A}$ \\
\hline & $\mathrm{CV}(\%)$ & 13,4 & 10,4 & 13,0 & 14,5 & 9,6 \\
\hline \multirow[t]{5}{*}{ NB } & IAC86-2210 (T) & 2,25 & $2,75 \mathrm{~B}$ & $4,25 \mathrm{~B}$ & $4,50 \mathrm{~B}$ & 3,55 \\
\hline & IAC86-2210 (NT) & 1,90 & $4,00 \mathrm{~A}$ & $5,50 \mathrm{~A}$ & $5,75 \mathrm{~A}$ & 3,34 \\
\hline & SP80-1842 (T) & 1,50 & $2,75 \mathrm{~B}$ & $2,75 \mathrm{~B}$ & $3,50 \mathrm{~B}$ & 3,33 \\
\hline & SP80-1842 (NT) & 1,50 & $4,25 \mathrm{~A}$ & $4,50 \mathrm{~A}$ & $5,25 \mathrm{~A}$ & 3,61 \\
\hline & CV $(\%)$ & 31,6 & 30,0 & 16,6 & 17,2 & 5,9 \\
\hline \multirow[t]{5}{*}{$\% \mathrm{NB}$} & IAC86-2210 (T) & 16,37 & $21,70 \mathrm{~B}$ & 33,42 B & $30,28 \mathrm{~B}$ & 14,66 \\
\hline & IAC86-2210(NT) & 14,2 & $28,09 \mathrm{~A}$ & $39,94 \mathrm{~A}$ & $37,26 \mathrm{~A}$ & 14,54 \\
\hline & SP80-1842 (T) & 11,58 & $25,00 \mathrm{~B}$ & $24,32 \mathrm{~B}$ & $26,30 \mathrm{~B}$ & 15,41 \\
\hline & SP80-1842 (NT) & 10,99 & $33,63 \mathrm{~A}$ & $36,61 \mathrm{~A}$ & $31,14 \mathrm{~A}$ & 19,06 \\
\hline & CV $(\%)$ & 22,9 & 33,7 & 14,3 & 17,4 & 12,4 \\
\hline
\end{tabular}

Médias na coluna seguidas de letras diferentes são diferentes entre si a 5\% de probabilidade pelo teste de Tukey.

NC: número de colmos; NB: número de brotões; \%NB: porcentagem do número de brotões.

T: tutorada; NT: não tutorada.

A esses resultados contrapõem-se aqueles de BERDING et al. (2005) e BonNETT et al. (2005), segundo os quais os valores de massa dos colmos foram superiores nos tratamentos com plantas mantidas eretas, fator este também correlacionado com o comprimento de colmos. Nos colmos tombados, no entanto, os autores constataram um decréscimo no valor das massas após o tombamento das plantas, devido, principalmente, à morte de grande parte dos perfilhos.

Para massa de brotões por metro, houve diferenças significativas no manejo de tutoramento dos colmos, aos 50 e $140 \mathrm{DAT}$, nas duas variedades estudadas; na primeira data, verificou-se mais massa de brotões no tratamento tombado, enquanto na segunda época, constatou-se no tratamento tutorado (Tabela 3). Segundo BERDing et al. (2005) e BonNETT et al. (2005), os valores das massas de brotões nas parcelas com plantas tombadas foram maiores quando comparados aos daqueles na cana ereta, visto que, nas parcelas com tombamento, esses brotos tinham condições favoráveis para seu desenvolvimento. Neste estudo, a verificação de maiores valores de massa de brotões no tratamento ereto, aos $140 \mathrm{DAT}$, pode ser explicada pela quantidade superior desses rebentos nas primeiras datas após o tombamento. Com o passar do tempo, deu-se o crescimento desses brotos até a fase adulta, enquanto no tratamento ereto, a aparição dos brotos foi gradual e contínua, relativamente à característica do genótipo, além de fatores ambientais e da maturação dos colmos, conforme BonNETT et al. (2001, 2005).

Para a porcentagem da massa de brotões em relação aos colmos adultos por metro, houve diferença significativa para o tratamento de manejo, dos 50 aos 140 dias após o tombamento das parcelas; aos 50 e 95 dias, houve mais interferência da produção de brotões na cana tombada; aos 140 dias essa diferença foi maior no tratamento tutorado (Tabela 3).

Esses resultados assemelham-se aos citados anteriormente para massa de brotões por metro. Notase aumento da porcentagem da massa de brotões com o decorrer do tempo, para as duas variedades, tanto no tratamento ereto quanto naquele com tombamento. $\mathrm{Na}$ variedade IAC86-2210, entretanto, o maior valor no tratamento ereto foi de $31,1 \%$ enquanto no tombado foi de $36,4 \%$; na variedade SP80-1842 os valores máximos foram de $32,8 \%$ e $39,3 \%$, respectivamente, nos tratamentos com plantas eretas e tombadas. 
Tabela 3. Massa de colmos, massa de brotões e porcentagem da massa de brotões em relação ao número de colmos por metro, em variedades de cana-de-açúcar, em função do manejo de plantas e dos dias após o tombamento. Jaú (SP), safra de 2003/2004

\begin{tabular}{|c|c|c|c|c|c|c|}
\hline \multirow{2}{*}{ Parâmetros } & \multirow{2}{*}{ Variedades } & \multicolumn{5}{|c|}{ Dias após o tombamento } \\
\hline & & 5 & 50 & 95 & 140 & 185 \\
\hline & & & 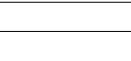 & $-\mathrm{kg}$ & 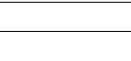 & \\
\hline \multirow[t]{5}{*}{$\mathrm{MC}$} & IAC86-2210 (T) & 16,02 & $14,22 \mathrm{~B}$ & 20,35 & 27,60 & 16,60 \\
\hline & IAC86-2210 (NT) & 15,55 & $17,12 \mathrm{~A}$ & 19,07 & 24,92 & 17,00 \\
\hline & SP80-1842 (T) & 14,37 & $15,62 \mathrm{~B}$ & 16,02 & 24,85 & 17,92 \\
\hline & SP80-1842 (NT) & 13,77 & $16,72 \mathrm{~A}$ & 16,85 & 27,95 & 18,67 \\
\hline & CV $(\%)$ & 15,8 & 9,5 & 11,7 & 10,0 & 12,1 \\
\hline \multirow[t]{5}{*}{ MB } & IAC86-2210 (T) & 2,28 & $2,14 \mathrm{~B}$ & 6,30 & $8,55 \mathrm{~A}$ & 5,20 \\
\hline & IAC86-2210 (NT) & 2,01 & $5,00 \mathrm{~A}$ & 6,80 & $6,35 \mathrm{~B}$ & 5,08 \\
\hline & SP80-1842 (T) & 1,54 & $3,57 \mathrm{~B}$ & 5,22 & $7,42 \mathrm{~A}$ & 5,27 \\
\hline & SP80-1842 (NT) & 1,64 & $4,32 \mathrm{~A}$ & 6,60 & $5,22 \mathrm{~B}$ & 5,19 \\
\hline & $\mathrm{CV}(\%)$ & 15,4 & 25,9 & 16,6 & 20,5 & 4,8 \\
\hline \multirow[t]{5}{*}{$\% \mathrm{MB}$} & IAC86-2210 (T) & 14,32 & $15,12 \mathrm{~B}$ & 31,07 B & $30,80 \mathrm{~A}$ & 11,62 \\
\hline & IAC86-2210 (NT) & 12,86 & $29,03 \mathrm{~A}$ & $36,35 \mathrm{~A}$ & $25,51 \mathrm{~B}$ & 10,18 \\
\hline & SP80-1842 (T) & 10,70 & $22,89 \mathrm{~B}$ & $32,81 \mathrm{~B}$ & $29,70 \mathrm{~A}$ & 10,17 \\
\hline & SP80-1842 (NT) & 11,87 & $25,70 \mathrm{~A}$ & $39,33 \mathrm{~A}$ & $18,83 \mathrm{~B}$ & 12,09 \\
\hline & $\mathrm{CV}(\%)$ & 12,6 & 24,2 & 21,7 & 19,4 & 12,7 \\
\hline
\end{tabular}

Médias na coluna seguidas de letras diferentes são diferentes entre si a $5 \%$ de probabilidade pelo teste de Tukey.

MC: massa de colmos; MB: massa de brotões; \%MB: porcentagem da massa de brotões.

T: tutorada; NT: não tutorada.

Esses resultados são concordantes com os de JACKSON et al. (2000), segundo os quais, a interferência da massa de brotões no total de cana produzida foi média a intensa, sendo variável entre $5 \%$ e $25 \%$. BERDing e HuRney (2000) também obtiveram aumento de $26,3 \%$ na produção da cultura, devido aos brotões, cuja massa entre as variedades foi variável de 10,7\% a 20,0\%, na colheita final. Para BonnetT et al. (2001), a contribuição dos brotões pode ser de 3,0\% a 30,0\% na massa do material colhido.

Os dados de número total de colmos por hectare estão relacionados na tabela 4. Houve diferenças significativas aos 50 e $95 \mathrm{DAT}$, quando esse valor foi maior no tratamento tombado, em todas as variedades, do mesmo modo como verificado para número de colmos por metro (Tabela 2).

Em relação ao número total de brotões por hectare, houve diferenças significativas em favor do tombamento aos 50 e $95 \mathrm{DAT}$, nas duas variedades. Esses resultados assemelham-se àqueles explicados anteriormente para número de brotões por metro linear (Tabela 4).

Para a proporção de número total de brotões por hectare em relação ao número total de colmos, os valores foram significativamente maiores no tratamento tombado, para a variedade IAC86-2210, apenas aos 50 e 185 DAT; na SP80-1842 essa diferença foi verificada também aos 95 dias.

Os valores percentuais de brotões por hectare não foram tão elevados quanto os verificados para percentual de brotões por metro, relacionados na tabela 2, demonstrando-se a redução do efeito do tombamento com o aumento da área experimental.

Verificaram-se também, os efeitos do tombamento na produção de brotões até os 95 DAT. Após o tombamento, o comportamento da cana é como o de uma planta nova, com elevada produção de auxina e, portanto, com muito estímulo ao crescimento (TAiz e ZeIger, 2004). Por conseguinte, na tomada de decisão do manejo da colheita de talhões com tombamento de colmos, estes devem ser colhidos no fim da safra e não imediatamente após seu tombamento.

Os dados de produtividade de cana estão inseridos na tabela 5. Foram constatadas diferenças significativas dentro de variedades, obtendo-se mais produtividade de colmos no tratamento tombado. 
Tabela 4. Número de colmos, número de brotões e porcentagem do número de brotões em relação ao número de colmos por hectare em variedades de cana-de-açúcar, em função do manejo de plantas e dos dias após o tombamento. Jaú (SP), safra 2003/2004

\begin{tabular}{|c|c|c|c|c|c|c|}
\hline \multirow{2}{*}{ Parâmetros } & \multirow{2}{*}{ Variedades } & \multicolumn{5}{|c|}{ Dias após o tombamento } \\
\hline & & 5 & 50 & 95 & 140 & 185 \\
\hline & & & & $\mathrm{n}^{\mathrm{o}}$ & 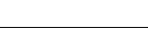 & \\
\hline \multirow[t]{5}{*}{$\mathrm{NCH}$} & IAC86-2210 (T) & 59965,17 & 54631,97 В & $50232,08 \mathrm{~B}$ & 44498,89 & 43598,91 \\
\hline & IAC86-2210 (NT) & 62331,78 & $66365,00 \mathrm{~A}$ & $56531,92 \mathrm{~A}$ & 45232,20 & 44598,89 \\
\hline & SP80-1842 (T) & 63565,08 & 55765,27 B & 56298,59 B & 51098,72 & 45332,20 \\
\hline & SP80-1842 (NT) & 65265,04 & $69131,61 \mathrm{~A}$ & $64865,05 \mathrm{~A}$ & 55165,29 & 51365,38 \\
\hline & $\mathrm{CV}(\%)$ & 6,8 & 7,6 & 7,6 & 9,2 & 8,7 \\
\hline \multirow[t]{5}{*}{$\mathrm{NBH}$} & IAC86-2210 (T) & 7999,80 & 7299,82 B & 4533,22 B & 3066,59 & 3133,26 \\
\hline & IAC86-2210 (NT) & 6833,16 & $10899,72 \mathrm{~A}$ & $5599,86 \mathrm{~A}$ & 3199,92 & 4233,23 \\
\hline & SP80-1842 (T) & 6333,18 & 5199,87 B & 3933,24 B & 2599,94 & 3433,25 \\
\hline & SP80-1842 (NT) & 6099,85 & $10099,75 \mathrm{~A}$ & $6166,52 \mathrm{~A}$ & 3099,92 & 4799,88 \\
\hline & CV $(\%)$ & 10,9 & 14,6 & 11,6 & 13,3 & 12,7 \\
\hline \multirow[t]{5}{*}{$\% \mathrm{NBH}$} & IAC86-2210 (T) & 13,31 & $13,28 \mathrm{~B}$ & 9,01 & 6,95 & $7,25 \mathrm{~B}$ \\
\hline & IAC86-2210 (NT) & 10,98 & $16,43 \mathrm{~A}$ & 9,90 & 7,10 & $9,52 \mathrm{~A}$ \\
\hline & SP80-1842 (T) & 10,01 & $9,38 \mathrm{~B}$ & $7,00 \mathrm{~B}$ & 5,09 & $7,35 \mathrm{~B}$ \\
\hline & SP80-1842 (NT) & 9,35 & $14,57 \mathrm{~A}$ & $9,55 \mathrm{~A}$ & 5,65 & $9,46 \mathrm{~A}$ \\
\hline & CV $(\%)$ & 13,2 & 11,2 & 6,6 & 7,3 & 12,7 \\
\hline
\end{tabular}

Médias na coluna seguidas de letras diferentes são diferentes entre si a $5 \%$ de probabilidade pelo teste de Tukey.

$\mathrm{NCH}$ : número de colmos por hectare; NBH: número de brotões por hectare; \% NBH: porcentagem do número de brotões por hectare

T: tutorada; NT: não tutorada.

Tabela 5. Valores médios de produtividade de colmos de cana-de-açúcar em função de variedades mantidas eretas, tutoradas $(\mathrm{T})$, e com hábito de crescimento natural, não tutoradas (NT) e índice relativo. Jaú (SP), safra 2003/2004

\begin{tabular}{lcc}
\hline Variedades & Colmos & $\mathrm{IR}$ \\
\hline & $\mathrm{t} \mathrm{ha}^{-1}$ & $\%$ \\
IAC86-2210 (T) & $103,76 \mathrm{~B}$ & 85,1 \\
IAC86-2210 (NT) & $121,87 \mathrm{~A}$ & 100,0 \\
SP80-1842 (T) & $115,71 \mathrm{~B}$ & 89,2 \\
SP80-1842 (NT) & $129,71 \mathrm{~A}$ & 100,0 \\
\hline CV $(\%)$ & 3,6 & \\
\hline
\end{tabular}

Médias na coluna seguidas de letras diferentes são diferentes entre si a $5 \%$ de probabilidade pelo teste de Tukey.

IR: índice relativo percentual entre plantas tutoradas e não tutoradas.

Para as variedades IAC86-2210 e SP80-1842 as diferenças em favor do tratamento tombado foram de $14,9 \%$ e $10,8 \%$ respectivamente. No entanto, CAPUTO (2003), em trabalho realizado no Brasil, obteve, na colheita, produção significativamente maior de quantidade de colmos no tratamento tutorado, aos 300
DAT, com valores de aumento percentual de $12,8 \%$ na RB835486 e de 20,4\% na SP87-344, sem qualquer menção à presença de brotões nas parcelas. SINGH et al. (2000), em trabalho realizado na Austrália, verificaram produção de $11 \%$ a $19 \%$ mais cana no tratamento tutorado, sendo significativamente maior à do tombado.

As diferenças de produtividade em relação ao tratamento tombado, relatadas neste trabalho, são reflexos do aumento dos perfilhos, promovidos pelo incremento de brotões. Essa maior produtividade, entretanto, não está associada à qualidade da matéria-prima, pois de acordo com BERDING et al. (2005), nesses perfilhos novos o teor de sacarose é pequeno e o de açúcares redutores é elevado. Portanto, estudos sobre o efeito do tombamento e dos brotões na qualidade tecnológica da cana-de-açúcar também devem ser realizados, como os de CARLIN et al. (2005).

\section{CONCLUSÕES}

1. A emissão de brotões na cana-de-açúcar é favorecida pelo tombamento de seus colmos. 
2. Os parâmetros biométricos comprimento e número de colmos são incrementados até 95 dias após o tombamento dos colmos.

3. A colheita de colmos deve ser realizada após 95 dias do seu tombamento, a fim de se evitar excesso de brotões na matéria-prima.

4. A produtividade agrícola das variedades IAC86-2210 e SP80-1842 de cana-de-açúcar aumenta com o tombamento dos colmos.

\section{AGRADECIMENTOS}

À CAPES, pela bolsa de Mestrado concedida à primeira autora, e à FAPESP (Processo $\mathrm{n}^{\circ} .2003$ / 01135-5), pelo apoio financeiro ao projeto de pesquisa.

\section{REFERÊNCIAS}

AMAYA, A.; GOMEZ, A.L.; BUITRAGO, J.T.; MORENO, C.A.; CASSALETT, C. Characterization of lodging in sugarcane. In: AUSTRALIAN SOCIETY OF SUGAR CANE TECHNOLOGISTS CONFERENCE, 22., 2000, Bundaberg. Proceedings... Bundaberg: D.M. Hogarth, 2000. p.321-327.

BERDING, N.; HURNEY, A.P. Suckering: a facet of ideotype selection and declining CCS in the tropics. In: AUSTRALIAN SOCIETY OF SUGAR CANE TECHNOLOGISTS CONFERENCE, 22., 2000, Bundaberg. Proceedings... Bundaberg: D.M. Hogarth, 2000. p.147-152.

BERDING, N.; HURNEY, A.P.; SALTER, B.; BONNETT, G.D. Agronomic impact of sucker development in sugarcane under different environmental conditions. Field Crops Research, Amsterdam, v.92, n.1, p.203-217, 2005.

BERDING, N.; HURNEY, A.P. Flowering and lodging, physiological-based traits affecting cane and sugar yield. What do we know oh their control mechanisms and how do we manage them? Field Crops Research, Amsterdam, v.92, n.1, p.261-275, 2005.

BONNETT, G.D.; SALTER, B.; ALBERTSON, P.L. Biology of suckers: late-formed shoots in sugarcane. Annals of Applied Biology, Wellesbourne, v.138, n.1, p.17-26, 2001.

BONNETT, G.D.; BERDING, N.; SALTER, B.; HURNEY, A.P. Suckering in the wet tropics: consequences, environmental stimuli and potential solutions. In: THE AUSTRALIAN SOCIETY OF SUGAR CANE TECHNOLOGISTS, 26., 2004, Bundaberg. Proceedings... Bundaberg: D.M. Hogarth, 2004. 1 CD-ROM.

BONNETT, G.D.; SALTER, B.; BERDING, N.; HURNEY, A.P. Environmental stimuli promoting sucker initiation in sugarcane. Field Crops Research, Amsterdam, v.92, n.1, p.219-230, 2005.

BRASIL. MINISTÉRIO DA AGRICULTURA, PECUÁRIA E ABASTECIMENTO. Plano Nacional de Agroenergia: 2006-2011. 2.ed. Brasília: Embrapa Informação Tecnológica, 2006. 114p.
CAPUTO, M.M. Efeito do tombamento nas características tecnológicas e biométricas de variedades de cana-de-açúcar. 2003. 63f. Monografia (Graduação em Agronomia) - Faculdade de Ciências Agrárias e Veterinárias - UNESP, Jaboticabal.

CARLIN, S.D.; SILVA, M.A.; ROSSETTO, R. Interferência do tombamento na qualidade da matéria-prima da cana-deaçúcar. STAB - Açúcar Álcool e Subprodutos, Piracicaba, v.24, n.2, p.36-40, 2005.

COPERSUCAR. Quarta geração de variedades de cana-de-açúcar Copersucar. Piracicaba: Centro de Tecnologia Copersucar, 1993. p.12-15 (Boletim Técnico Copersucar, Edição Especial)

HURNEY, A.P.; BERDING, N. Impact of suckering and lodging on productivity of cultivars in the wet tropics. In: AUSTRALIAN SOCIETY OF SUGAR CANE TECHNOLOGISTS CONFERENCE, 22., 2000, Bundaberg. Proceedings... Bundaberg: D.M. Hogarth, 2000. p.328-333.

JACKSON, P.; BONNETT, G.D.; CHUDLEIGH,P.;HOGARTH, M.; WOOD, A. The relative importance of cane yield and traits affecting CCS in sugarcane varieties. In: AUSTRALIANSOCIETY OFSUGAR CANE TECHNOLOGIST CONFERENCE, 22., 2000, Bundaberg. Proceedings... Bundaberg: D.M. Hogarth, 2000. p.23-29.

LANDELL, M.G.A.; SILVA, M.A. Manual do experimentador: melhoramento da cana-de-açúcar. In: Metodologia de Experimentação: ensaios de competição em cana-de-açúcar. Pindorama: Instituto Agronômico, 1995, p.3-9.

LANDELL, M.G.A.; CAMPANA, M.P.; FIGUEIREDO, P.; ZIMBACK, L.; SILVA, M.A.; PRADO, H. Novas variedades de cana-de-açúcar. Campinas: Instituto Agronômico, 1997. 28p. (Boletim técnico, 169).

PRADO, H. Solos do Brasil: gênese, morfologia, classificação, levantamento e manejo. 3.ed. Piracicaba: FEALQ, 2003. 275p.

RAMESH, P.; MAHADEVASWAMY,M. Effect of formative phase drought on different classes of shoot, shoot mortality, cane attributes, yield and quality of tour sugarcane cultivars. Journal of Agronomy \& Crop Science, Berlin, v.185, n.4, p.249-258, 2000.

SILVA, M.A.; CAPUTO, M.M. Effect of lodging on growth, yield and cane quality of sugarcane varieties grown in Brazil. In: INTERNATIONAL SOCIETY OF SUGAR CANE TECHNOLOGISTS CONGRESS, 25., 2005, Guatemala. Proceedings... Guatemala: D.M. Hogarth, 2005. p.176-183.

SINGH, G.; CHAPMAN, S.C.; JACKSON, P.A.; LAWN, R.J. Lodging - A major constraint to high yield and CCS in the wet and dry tropics. In: AUSTRALIAN SOCIETY OF SUGAR CANE TECHNOLOGISTS CONFERENCE, 22., 2000, Bundaberg. Proceedings. Bundaberg: D.M. Hogarth, 2000. p.315-321.

SKINNER, J.C. Grading varieties for selection. In: INTERNATIONAL SOCIETY OF SUGAR CANE TECHNOLOGISTS CONGRESS, 12., 1965, San Juan. Proceedings. Amsterdam: International Society of Sugar Cane Technologists, 1967. p.938-949.

TAIZ, L.; ZEIGER, E. Fisiologia Vegetal. 3.ed. Porto Alegre: Artmed, 2004. p.449-484. 